\title{
Reaching out of the echo chamber
}

Facets 3, 682-694 (2018)

Social media platform Twitter is potentially a powerful outreach tool for scientists.

However, at what point do communications about scientific findings transcend from being discussions between colleagues to reach broader, non-scientific audiences? Isabelle Côté and Emily Darling analysed the followers of 100 faculty members studying ecology and evolutionary biology and found that only those with more than $\sim 1,000$ followers have a sufficiently heterogeneous cohort to reach audiences beyond their professional peers with their scientific tweets.

Côté and Darling attempted to identify the transition from 'inreach' (promotion of scientific findings primarily to other scientists) to 'outreach' by categorizing the academics' followers into several occupational classes according to their Twitter profile descriptions. The authors found that scientists generally have lower 'reaches' (total followers of followers) compared to other classes in the study such as 'media' and 'decision-makers', but once a scientist's following had grown to incorporate members of the other classes, the potential reach of scientific findings grew significantly. 'Decision-makers' (for example, politicians and policymakers) seem to be the most challenging class to recruit, typically requiring a following of $\sim 2,200$ to attract their interest (even though, dishearteningly, decision-makers tend to use Twitter as a broadcasting tool rather than for dialogue).

Ultimately, scientists keen on using Twitter for science communication and diffusion of their own research need to invest time in building up a diverse following through focused and sustained tweeting.

Paul Woods

Published online: 17 July 2018

https://doi.org/10.1038/s41550-018-0554-5 